\title{
ELICITED IMITATION IN LANGUAGE ASSESSMENT: A TOOL FOR FORMULATING AND EVALUATING TREATMENT PROGRAMS
}

\author{
ARTHUR H. SCHWARTZ \\ Department of Biocommunicutions. University of Alabama in Birmingham. Birmingham, Alabama \\ 35226 \\ DAVID A. DALY \\ Section of Spect and Hearing Seiences. University of Michigan, Ann Arbor, Michigan 48109
}

Four sifferent clinical populations were administered an elicited imitation task before and after therapy to determine the usefulness of elicited imitati $n$ procedures for formulating and evaluating language treatment programs. Oildren's imitations were analyzed according to the numbers and patterns of omission errors, substitution errors, and correct responses. Results indicated that (1) pattems of responding could be identified; (2) specific pattems were associated with different clinical populations; (3) performance on pretherapy measures coutd be efficiently analyzed and utilized for formulating language ireatment programs; and (4) changes ir posttherapy performance could be readily evaluated using this procedure. The data suggest that the elicited imitation procedures can be effectively used to increase the precision of the evaluation and clinical programming of children with language disorders.

\section{Introduction}

In 1968 Slobin and Welsh described a procedure known as elicited imitation (EI) to examine a child's underlying linguistic competence. They based their procedure on the assumption that, when given a model sentence to imitate, the child would repeat the sentence using productive rules commensurate with, but not exceeding, his or her level of linguistic development. Their data revealed that if the sentence were beyond the child's normal sentence processing ability, the child was likely to systematically recode the model sentence into a more simplified version. Slobin and Welsh maintained that by systematically varying key grammatical structures within model sentences, and analyzing discrepancies between the model and child's version, it would be possible to efficiently evaluate linguistic performance.

Even though Slobin and Welsh presented elicited imitation as an experimental psycholinguistic tool that should be regarded as a conservative estimate of linguistic competence, several attempts have been mode to use EI procedures clinically (Gray and Ryan, 1973; Carrow, 1974a,b; Schwartz and Daly, 1974). Elicited imitation procedures appear to offer clinicians an efficient and relatively simple measure of language performance, in that the results reportedly agree closely with data obtained through Developmental Sentence Scoring procedures (Cornelius, 
1974), and with results obtained through analysis of spontaneous language samples (Trauericht et al. . 1974). The data indicate that elicited imitation procedures are diagnostically useful and warrant serious consideration by clinicians.

What has been little studied at this point, and what was examined in the present investigation, was whether elicited imitation procedures could be used to identify specific grammatical structures which could provide a basis upon which to formulate an effective language treatment program.

\section{Procedures}

\section{Subjects}

Forty children were selected from a population of 96 clients attending the University of Michigan Speech and Hearing Camp (Shady Trails), a 7.week residential summer ramp that provides intensive treatment programs for individuals with speech and language problems. Subjects ranged in age from 7 years, 6 months, to 19 years, with a mean age of 11 years, 4 months. All subjects had previously undergone an average of 3 years of individual or group speech and language therapy in their home environments.

\section{Subject Grouping}

All 96 campers ware initially tested on the elicited imitation measure. From this population 40 children were selected for inclusion in the present study. The EI procedure was used only to evaluate each child's proficiency at using particular grammatical constructions and not for quantifying the degree of language impairment. Several additional speech and language measures were employed at camp to determine the severity of speech and/or language disorder, as well as data from reports provided by referring speech and language pathologists.

After reviewing the referral information available in each $c^{\text {'. }}$ ild's folder and the results of comprehensive camp speech and language evaluwtions, three speech pathologists assigned each of the 40 subjects to one of the following four intervention strategies:

(1) A language group $(N=10)$ in which a minimum of $75 \%$ of individual and small group therapy sessions ( 45 clock hours) was devoted to language therapy;

(2) A combined language-articulation group $(N=10)$ in which $50 \%$ of individual and small group therapy sessions dealt with syntax usage and $50 \%$ were concerned with the correction of specific speech sound misarticulations;

(3) An articulation group $(N=10)$ who received $75 \%$ (45 clock hours) of therapy time to correct specific articulation errors; and

(4) A fluency group $(N=10)$, which acted as a control group, received therapy for the modification of stuttering, with no time or effort devoted to correcting specific grammatical stuctures. 


\section{Test Description and Administration Procedures}

During the first 3 days of the camp season, each child was administered a 55-item elicited imitation measure. The measure used in the present study was the Programmed Conditioning for Language Test (PCLT) described by Gray and Ryan (1973). The PCLT is an elicited imitation measure expressly designed for the purpose of placing a language disordered child within the various programs described by Gray and Ryan (1973). Stimulus items in the PCLT were used because of the key grammatical structures assessed by this measure, its adaptability to the scoring protocol investigated in the present study, and its availability from the authors.

Each child was tested individually by a trained evaluator in a quiet, soundtreated room that was isolated from other camp activities. Prior to the administration of the test, the examiner instructed the child to imitate the model sentences following the cue phrase, "Say what I say." All responses were tape recorded on a Wollensak magnetic tape recorder (T-1500) for subsequent analysis.

\section{Scoring Procedures}

Because of the grammatical complexity and reported frequency of erroneous grammatical rule usage in language disordered populations (Menyuk, 1964; Leonard, 1972), the present study was concerned with three different grammatical operations: (1) auxiliary verbs; (2) nonauxiliary verb forms; and (3) interrogative reversals. There were a total of 23 auxiliary verb constructions, 19 nonauxiliary verb forms, and 11 interrogative reversals on the PCLT. Each child's performance was measured by counting the number of correct and error responses for the target grammatical constructions. A more extensive account of the scoring procedures has been presented elsewhere (Schwartz and Daly, 1976). Basically, error responses were subdivided into two patterns: (a) omission errors characterized by a failure to include a structure or structural marker in the repetition of the model sentence, and (b) substitution errors in which another grammatical structure or structural marker was used in place of the target construction in the model sentence. Comparisons of the performance of subjects in each tr atment group were made to determine if patterns of responding could be iuentified and if particular patterns were associated with children in different treatment groups.

A diagnostic profile for each child, indicating errors of responding on each grammatical construction, was presented and discussed with each child's clinician and clinical supervisor. Recommendations regarding the specific grammatical structures and instructional sequences to be taught were made. A set of behavioral objectives for each child was formulated and implemented. Children in each treatment group received a minimum of 60 clock hours of individual or small group therapy sessions prior to posttesting. During the seventh week of camp, the elicited imitation measure was readministered to each subject. An analysis of the 
number of errors and types of response patterns was again made for each subject. Comparisons between goups for pre-and posttest measurements were made to dermine the effects of the rapy on the number and types of error responses on each target construction.

\section{Results}

To test for interexaminer agreement on the elicited imitation task, 5 of the 40 children were randomly selected and tested by two speech pathologists. Percentages of agreements on buth pre- and posttherapy assessments were all above $90 \%$. with a mean agreement figure of $94 \%$.

A multivariate analysis of variance (Barr and Goodnight, 1972) was performed

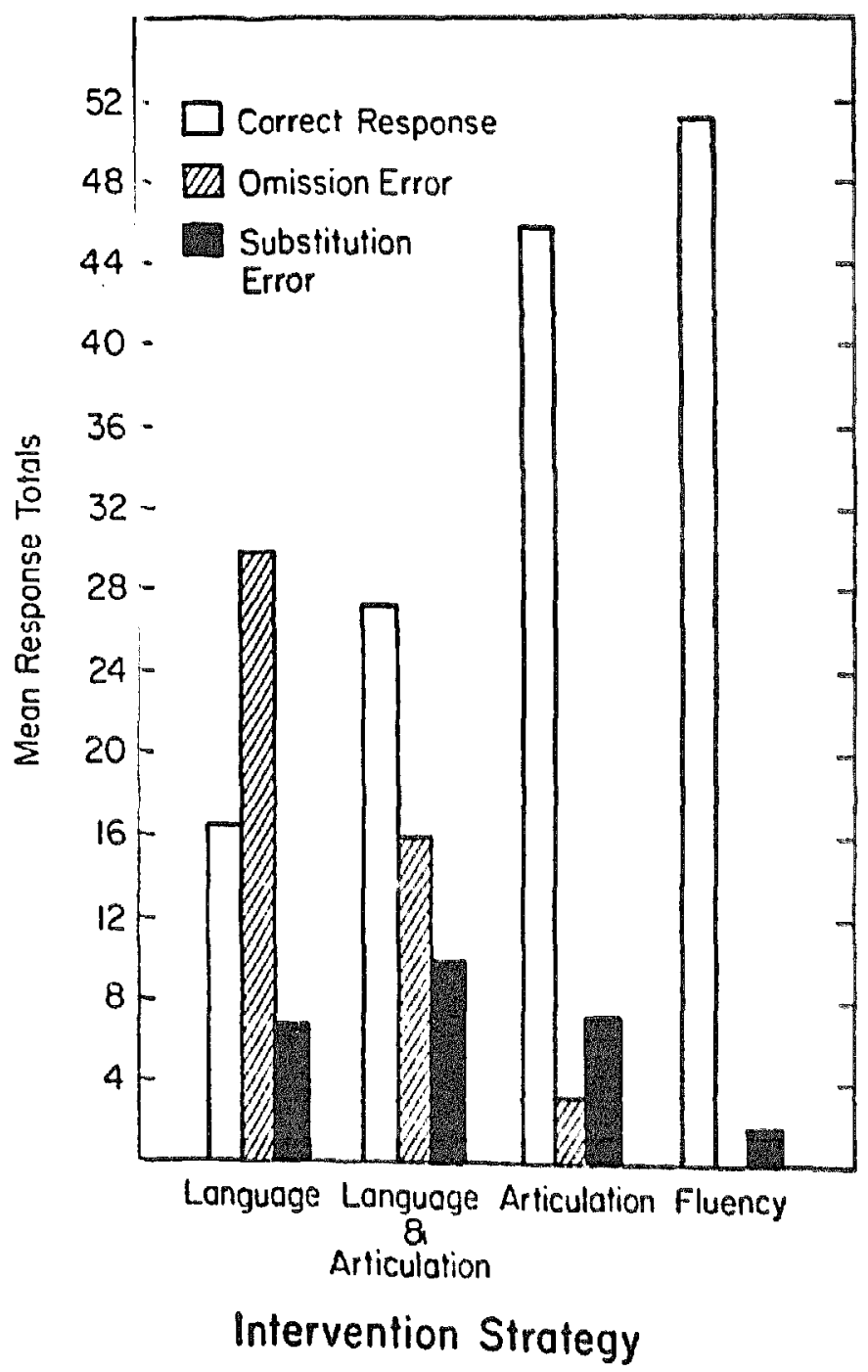

Fig. 1. Mean number of cc rrect responscs, omission errors, and substitution emors on pretherapy administration of the PCLT elicited imitation task. 
to analyze the pretherapy response patterns for subjects in each of the four different intervention strategies. The results of this analysis indicated that different patterns of responding on each grammatical construction could be identified and that particular patterns were associated with subjects in the different treatment groups. The mean number of correct responses and the mean number of omission and substitution errors for the subjects in each treatment group on the pretherapy administration of the elicited imitation task are shown in Fig. 1.

Subjects in the language group made significantly $(\mathbb{P}<.05)$ fewer correct responses on sentences containing the key grammatical constructions $(\bar{X}=16.1)$ than did subjects in the other three groups. Significantly more omission errors $(\overline{\mathrm{X}}$ $=30.15$ ) were made by subjects in the language grout than were made by subjects in the combined language-articulation group $(\bar{X}=16.4)$, the articulation group $(\bar{X}=2.75)$. or the fuency group $(\bar{X}=0.30)$. A mxed error pattern seemed to characterize the responses of subjects in the combined language-articulation group, whereas subjects in the other treatment groups tended to show a consistent trend for either substitution or omission errors.

A comparison of the responses of the different intervention strategies was made using the multivariate analysis (MANOVA) to determine if significant differences existed between subjects in the various treatment groups. The results $s ?$ this analysis indicated that subjects in the language group and in the languagearticulation group differed significantly $(P<0.01)$ from the subjects in the articulation group and fluency group as well as fron each other $(P<0.01)$.

A second objective of the present study was to determine if the results of the audministration of the elicited imitation measure could be used to evaluate language therapy programs. Two measures were of particular importance: changes in the number of correct and error responses and differences in the patterns of error responses after therapy. Posttherapy performance on the elicited imitation measure was analyzed using the multivariate analysis of variance. As shown by the mean scores in Table 1, subjects in the language treatment group showed substantially significant $(P<0.01)$ increases in the number of correct responses for each grammatical construction as well as marked decre:ses in number of omission errors.

For correct use of auxiliary verbs, subjects in the combined languagearticulation group showed a significant $(P<0.01)$ increase from a mean of 10.1 to 15.2, with, a corresponding decrease in omission errors from 9.10 to 6.10. Although this group showed consistent decreases in the number of omission errors for other verb forms and interrogative reversals, the decrease was not significant. Table $l$ also reveals that subjects in the articulation group decreased in the number of omission errors significantly $(P<0.01)$ for sentences containing auxiliary verbs, but not for other grammatical structures. As expected, there were no significant changes in the response patterns of subjects in the fluency group. The results of analysis of posttherapy performance suggest that therapy programs 
TABLE 1

Mean Number of lesponses on Three Grammatical Structures for Each Treatment Group before and after Therapy

\begin{tabular}{|c|c|c|c|c|c|c|c|c|c|c|}
\hline \multirow{2}{*}{$\begin{array}{l}\text { Intervention } \\
\text { stragegy }\end{array}$} & & \multicolumn{3}{|c|}{ Auxiliary verbs } & \multicolumn{3}{|c|}{ Nonauxiliary verbs } & \multicolumn{3}{|c|}{$\begin{array}{l}\text { Interrogative } \\
\text { reversal }\end{array}$} \\
\hline & & $\mathrm{Ca}$ & 0 & $\mathbf{S}$ & C & 0 & $\mathbf{S}$ & C & 0 & $\mathbf{s}$ \\
\hline & Pre & 6.50 & 13.90 & 2.60 & 7.20 & 8.00 & 3.80 & 2.40 & 8.50 & 0.10 \\
\hline Language & Post & 11.00 & 8.90 & 3.10 & 8.90 & 5.50 & 4.60 & 4.80 & 6.20 & 0 \\
\hline & Pre & 10.10 & 9.10 & 3.80 & 10.80 & 3.80 & 4.40 & 6.40 & 3.00 & 1.60 \\
\hline $\begin{array}{l}\text { Language and } \\
\text { articulation }\end{array}$ & Post & 15.20 & 6.10 & 1.70 & 10.80 & 3.20 & 5.00 & 8.10 & 2.80 & 0.10 \\
\hline Articulation & $\begin{array}{l}\text { Pre } \\
\text { Post }\end{array}$ & $\begin{array}{l}19.10 \\
20.70\end{array}$ & $\begin{array}{l}2.10 \\
0.50\end{array}$ & $\begin{array}{l}1.80 \\
1.80\end{array}$ & $\begin{array}{l}16.20 \\
15.70\end{array}$ & $\begin{array}{l}0.90 \\
0.40\end{array}$ & $\begin{array}{l}1.90 \\
2.90\end{array}$ & $\begin{array}{l}10.60 \\
10.80\end{array}$ & $\begin{array}{l}0.40 \\
0.10\end{array}$ & $\begin{array}{c}0 \\
0.10\end{array}$ \\
\hline Fluency & $\begin{array}{l}\text { Pre } \\
\text { Post }\end{array}$ & $\begin{array}{l}22.20 \\
22.50\end{array}$ & $\begin{array}{c}0 \\
0.20\end{array}$ & $\begin{array}{l}0.80 \\
0.30\end{array}$ & $\begin{array}{l}18.30 \\
18.60\end{array}$ & $\begin{array}{l}0 \\
0\end{array}$ & $\begin{array}{l}0.70 \\
0.40\end{array}$ & $\begin{array}{l}11.00 \\
11.00\end{array}$ & $\begin{array}{l}0 \\
0\end{array}$ & $\begin{array}{l}0 \\
0\end{array}$ \\
\hline
\end{tabular}

${ }_{a} \mathrm{C}=$ correct; $\mathrm{O}=$ : omission; $\mathrm{S}=$ substitution.

based on the results from the elicited imitation procedure can have a significant effect of increasing the number of correct responses and decreasing the number and type of error responses ior language disordered children.

The effects of therapy for each treatment group are further illustrated in Fig. 2. This figure shows the mean difference scores on the three types of response patterns monitored on each grammatical construction for subjects in all four treatment groups. Of particular interest is the change in response patterns observed for children in the language therapy group. The mean increase in the number of correct responses for auxiliary verbs $(\bar{X}=+4.5)$, other verbs $(\bar{X}=+1.0)$, and interrogative reversals $(\vec{X}=+2.2)$, almost mirrors the mean decrease in the pattern of omission errors for each structure. Consultation with supervising clinicians indicated that of the 50 clock hours of language therapy received by subjects in the language therapy group, 25 were specifically concemed with auxiliary verb usage, 10 hours pertained to correct usage of interrogative reversal rules, and the remaining 15 hours were devoted to a diverse nun.'er of regular and irregular verb forms. Figure $2 b$ shows that subjects in the languas -articulation group showed even greater average increases in the correct usage of auxiliary verbs $(\bar{X}=+5.0)$, although they reportedly received an average of only 15 clock hours of therapy on this particular structure. The differences observed for the subjects in the articulation group were not significant. The stability of the subjects in the fluency group on the posttherapy measure provides support for the ability of the elicited imitation measure to detect errors in grammatical rule usage. 


\section{Discussion}

The finding that an elicited imitation measure idenified specific errors and crror patterns in syntactic rule usage has important clinical implications. Some measures of syntax that are currently employed require that utterances be obtained and

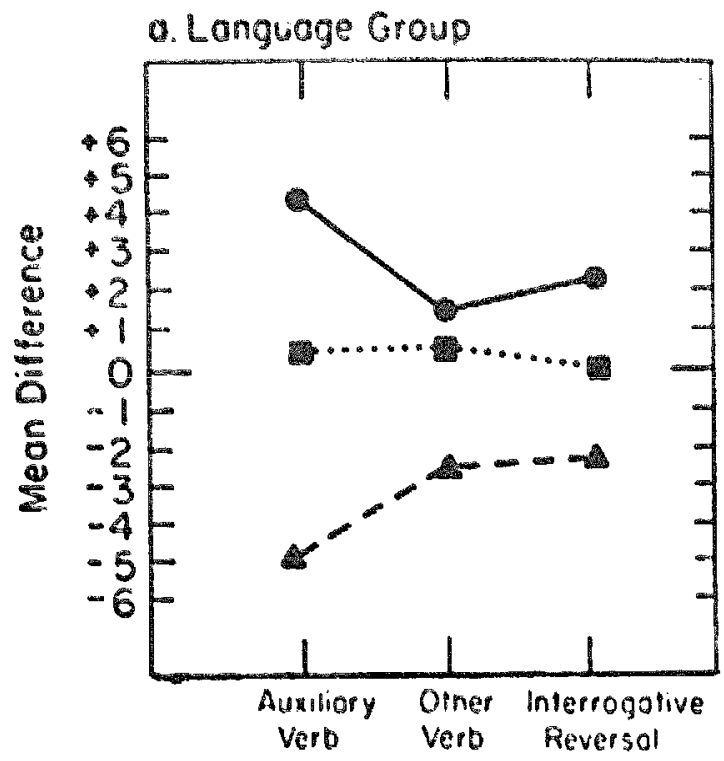

b. Longuage 8 Arpiculation Group
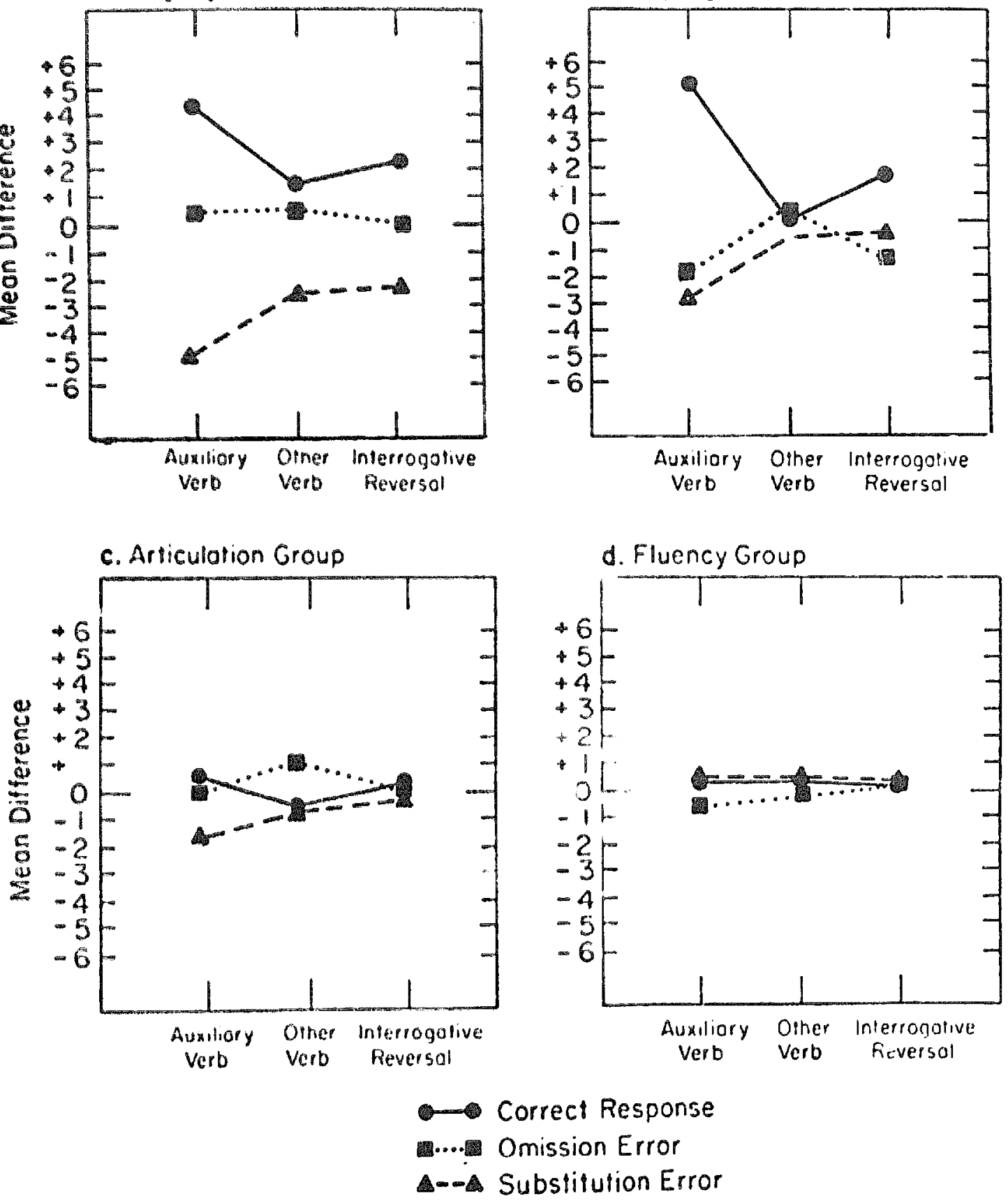

Fig. 2. Mean differences in correct, omission, and substitution responses on three grammatical structures for subjects in each intervention strategy as a function of therapy. 
analyzed in a complex and time consuming manner in order to obtain a representative appraisal of the child's grammatical competence. Even so, it has been pointed out that the context in which a language sample is obtained may preclude the appearance of some structures that the child can use.

In the present study, it took a total average of approximately 40 min to administer and to analyze a child's performance on an elicited imitation task. This represents a considerable savings of testing and scoring time in comparison to procedures such as developmental sentence analysis (Lee, 1974) or transforma. tional analysis (Chomsky, 1965).

In one of the early studies comparing the spontaneous imitations of children with their nonimitative speech, Ervin (1964) found that her children did not include structures in their imitations that were not present in spontaneous speech. That is, imitations did not exceed nonimitative utterances. Several other investigators (Brown, 1965; Odom et al., 1968; Menyuk, 1964; Rodd and Braine, 1971) have found that, on imitation tasks, children will recode sentences in a manner consistent with their grammatical capabilities.

While a child's imitations usually do not exceed spontaneous rule production, Slobin and Welsh (1968) have noted that if the sentence is within the child's "normal sentence processing span," it is possible for rote repetitions to occur. Only if the sentence exceeds the child's processing span will the child's responses reflect productive capacities. This poses a dilemma for clinicians and researchers. On one hand it appears that performance in rule production depends on memory span, yet on the other hand there is a sizeable body of information (Miller and Isard, 1963; Slobin, 1966; Gough, 1965) indicating that memory varies according to the grammatical complexity. This situation dictates cautious use and interpretation of data from elicited imitation measures. Nevertheless, the usefulness of an elicited imitation procedure is greatly enhanced if clinicians attend primarily to discrepancies between the model and the child's response. Since an accurate response may reflect rote processing, matches between model and response may not provide insight for diagnostic and programming decisions. Error responses, or discrepancies between model and response, however, are indicative of disruptions in the productive rule capacities of children. These findings indicate that the procedures used for obtaining, scoring, and analyzing performance on an elicited initation measure provide accurate clinical information in an efficient and un. complicated manner.

Recent investigations of children with language disorders suggest that their performance on elicited imitation and spontaneous language measures is consistent with earlier studies of normal speaking children. That is, performance on an El task does not exceed that on spontaneous measures. In a study comparing a group of language disordered and normal speaking children on the Lee's Developmental Sentence Scoring (1974) and Carrow's Elicited Imitation Inventory (Carrow, 1974b), Cornelius (1974) found a statistically significant correlation $(\boldsymbol{P}$ $<0.001$ ) between the two measures, indicating "a high relationship between the 
two methods of obtaining grammatical data." Similar findings were report 1 by Trauemicht et al. (1974) for a variety of syntactic structures measured by elicited imitation and analysis of spontaneous language of a group of language impaired children. Considering that the sampling of a greater variety of structures can be systematically obtained and analyzed using elicited imitation in a shorter period of time, it would appear that this procedure warrants serious consideration by clinicians.

One of the most interesting findings of this study was the effect of clinical programming on the number and patterns of errors on the posttherapy test administration. Subjects in the language group made significantly more omission type errors than subjects in the other groups. This finding is consistent with earlier research (Menyuk, 1964: Leonard, 1972) indicating that language disordered children tend to onit grammatical structires significantly more of ten than children with normal language. The results of this study indicate that on the posttests language disordered children showed significant changes in both the number of errors and patterns of error responses. These changes were in the number of omission errors and correct responses, while substitution errors remained relatively stable. This finding could mean that (1) in the acquisition of a structure, the child progressed from omission errors to correct errors, by-passing a phase of erroneous rule usage (substitution) or (2) that children shifted, in stage-wise fashion, from omission to substitution to correct rule production. Current studies (Leonard, 1972; Morehear and Ingham, 1975) indicate that language disordered children probably have, but do not use, the rules for generating specific linguistic structures. It is likely that the change in response patterns could be due to an "activation" of the child's capabilities to utilize the rules omitted on the pretest.

It was also interesting to note the changes in grammatical rule production that occurred for different groups receiving differing amounts of language therapy. Children in the language group received an average of 45 clock hours of language therapy, of which 25 clock hours were specifically concerned with auxiliary verbs. Subjects in this group showed a mean increase in accurate production of sentences with auxiliary verbs of 4.5 accurate responses. Subjects in the combined group (language and articulation therapy) showed a similar increase in accuracy of structure usage with an average of only 30 hours of language therapy, only 15 of which specifically concerned auxiliary verbs. One might ask how critical the additional 10 hours of auxiliary verb training was for the language disordered group. It is likely that since the subjects in the combined group already had greater proficiency in pruducing auxiliary verbs on the pretest $(\bar{X}=10.10)$, it did not require as much therapy to effect a similar change in rules production. This finding may also suggest that, in the acquisition of specific linguistic structures, there might be a plateauing effect that is somehow related to the treatment time. Gray and Ryan (1973) have described a format for facilitating acquisition of grammatical structures that gives attention to time. Using that format, most children will progress to a level of proficiency in structure if a certain response rate is main- 
tained. They maintain that as response rate declines, the accuracy of responding can decrease and that the duration of the program be prolonged.

In summary, the results of this study indicate that measures of elicitel imitation can be used to identify specific errors and patterns of responding, to differentiate certain clinical populations, and to plan to evaluate clinical programs. The findings suggest that clinicians can obtain detailed representations of a child's productive grammatical rules in an efficient, time-saving fashion using elicited imitation procedures. In light of the growing body of studies indicating that performance on this type of procedure is not spurious, it is felt that this procedure warrants serious consideration in decisions for clinical programming because of its ease and brevity of administration.

This study was conducted during the 1974 session of The University of Michigan Speech and Hearing Camp (Shady Trails). The authors wish to thank Carla Morand-Dustin for her assistance in data collection. Requests for reprints may be directed to David A. Daly, University of Michigan Section of Speech and Hearing Sciences, 1111 E. Catherine Street, Ann Arbor, Michigan 48109.

\section{References}

Barr, A. J., Goodnight, J. H. Statistical analysis system (SAS). Raleigh, N. C.: Department of Statistics, North Carolina State University, 1972.

Brown, R. Social psychology. New York: Free Press, 1965 pp. 286-305.

Carrow, E. A test using elicited imitations $n$ assessing grammatical structure in children. J. Speech Hearing Dis., 19\%4a, 39, 437-444.

Carrow, E. The Carrow elicited language inventory, Austin, Texas: Learning Concepts, 1974b.

Chomsky, N. Aspects of the theory of syntax. Carnbridge: MIT Press, 1965.

Comelius, S. A comparison of the elicited language inventory with developmental sentence scoring procedures in assessing language disorders in children. Unpublished master's thesis. University of Texas, Austin, 1974.

Ervin, S. Imitation and structure change in children's language. In E. H. Lenneberg (Ed.), New directions in the sludy of language. Cambridge: MIT Press, 1964.

Gough, P. B. Grammatical transformations and speed of understanding, I. Verb. Learn. Verb. Behav., 1965, 4, 107-117.

Gray, B. B., Ryan, B. P. A language program for the nonlanguage child. Champaign, Ill.: Research Press, 1973.

Lee, L. L. Developmental sentence analysis. Evanston, Ill.: Northwestem University Press, 1974. Leonard, L. L. What is deviant language? J. Speech Hearing Dis., 1972, 37, 427-446.

Menyuk, P. A comparison of the grammar of children with functionally deviant and normal speech. $J$. Speech Hearing Res., 1964 7, 109-121.

Miller, G. A., Isard, S. Some perceptual consequences of linguistic nules. J. Verb. Leam. Verb. Behav., 1963, 3, 217-223.

Morehead, D., Ingram, D. The development of base syntax in normal and linguistically deviant children. J. Speech Hearing Res., 1973, 16, 330-352

Odom, R. D. Leibert, R. M.. Hill, J. H. The effects of modeling cues, reward, and attentional set on the production of grammatical and ungrammatical constructions. J. Exp. Child Psychol., 1968, 6, 131-140. 
Rodd, L. J. Braine, M. D. Children's imitations of syntactic constructions as a measure of linguistic competence. J. Verb. Leam. Verb. Behav.. 1971, 10,430-443.

Schwarte. A. Haly. D. A. The use of elicited imitation measures for formulating and evaluating language therapy programs. Paper presented at the 49 h Annual Convention of the American Spech and Kearing Association. Las Vegas. 1974.

Schwartz. A.H. Daly. D. A. . Some explicit guidelines for constructing and scoring elicited imitation lasks. Lang. Specth Hearing Services Schools, 1976, 7, 33-41.

Slobin. D. 1. Grammatical transformations and sentence comprehension in childhond and adulthood. 1. Verb. Learm Verb. Behav. 1966, 5, 219-227.

Slonim. D. I. Welsh. C. A. Elicited imitation as a research tool in devel opmental psychologinguistics. Working Paper No. 10. Language Behavior Research Laboratory, University of California at Berkeley, 1968.

Traemicht. K. Sant. L. V.. Carpenter, J. M. The interrogative capacity of linguistically deviant chiden. Paper presented at the 49 th Annual Convention of the American Speech and Hearing Association. Las Vegas. 1974 